\title{
A detailed analysis of the propagation paths of high- frequency common mode currents in AC motors
}

\author{
Nidhal BOUCENNA ${ }^{1}$, Sami HLIOUI ${ }^{1,2}$ \\ ${ }^{1}$ SATIE, CNRS, Universud \\ 61, av Président Wilson, F-94230 Cachan, France \\ ${ }^{2}$ CNAM \\ Rue St Martin, 75141 Paris Cedex \\ nidhal.boucenna@satie-ens-cachan.fr
}

\author{
Bertrand REVOL ${ }^{1,4}$, François COSTA ${ }^{1,3}$ \\ ${ }^{3}$ Université Paris Est Créteil \\ place du 8 mai 1945, 93000 St Denis \\ ${ }^{4}$ ENS Cachan \\ 61, av Président Wilson, F-94230 Cachan, France
}

\begin{abstract}
- this paper describes the phenomena of propagation of common mode high-frequency currents (HF) in the metallic parts of AC machines supplied by pulse width modulation (PWM) inverters. A detailed analysis based on finite elements modeling is proposed to identify the privileged paths of these $\mathrm{HF}$ currents and parameters that rule this phenomenon.
\end{abstract}

Keywords- Induction motors, High frequency modeling, electromagnetic interferences, common mode voltage, Inverterinduced bearing current.

\section{INTRODUCTION}

PWM inverters have become the standard configuration for the supply and control of AC motors. However, this control strategy generates high $\mathrm{dv} / \mathrm{dt}$ and $\mathrm{di} / \mathrm{dt}$ which cause electrostatic stress in windings, bearings, and electromagnetic interference issues (EMI) [1, 4, and 5].

In the case of three-phased AC induction machines, the PWM drive induces a HF common mode voltage (Vcom) at the neutral terminal of windings. This one excites the different stray capacitances and a HF common mode current (Icom) is created. The flowing of these currents, i.e. through the stator core to ground, induces a HF common mode flux which causes a shaft voltage and subsequently bearings currents. This phenomena and the cycle of generation of bearing currents are well explained in [1-11].

This work is focused on the propagation of HF common mode currents in the metallic parts of AC machine, in order to identify their paths. For this purpose, a model based on finite elements analysis (FEA) has been established. This topic has already been studied in [5-9] using the same approach. However, these studies were based on FEA of a single lamination sheet of stator core. In addition, the particular paths of HF currents across laminated sheets were not well explained. Hence, a detailed FEA is firstly proposed in this paper, wherein more metallic parts of the machine are considered i.e. stator core, frame and end shields. Secondly, the paper deals with the effect of the grounding point position. Finally, a mutual inductance $\left(Z_{m}\right)$, between two adjacent iron sheets, has been identified and extracted from the FE simulation.

\section{IDENTIFICATION OF THE PROPAGATION PATH OF HIGH FREQUENCY COMMON MODE CURRENTS BY FEA}

\section{A. Assumptions:}

The aim of the analysis presented below is to determine the propagation paths of $\mathrm{HF}$ common mode currents in the different metallic parts of an $\mathrm{AC}$ induction machine. Using some assumptions presented and justified in [6,9], an axial symmetry (2D) model can be realized. These assumptions are listed below:

- The slots and teeth do not have a significant influence on the computed common mode flux [7]. Thus, they are neglected at this stage of modeling.

- The stator laminated core and the frame are supposed to be in perfect contact. The stray air gaps are neglected.

- In [1], authors explain that common mode currents are mainly due to the stray capacitances between the stator and the armature winding [1]. Therefore, the rotor is canceled from the following analysis.

- A copper layer is used to simulate the machine's windings, evenly distributed over the entire inner surface of the laminated core. An insulator layer is also placed between the laminated parts of the stator and the copper layer (Fig. 1).

- An insulator layer is placed between the end shields and the shaft (Fig. 1).

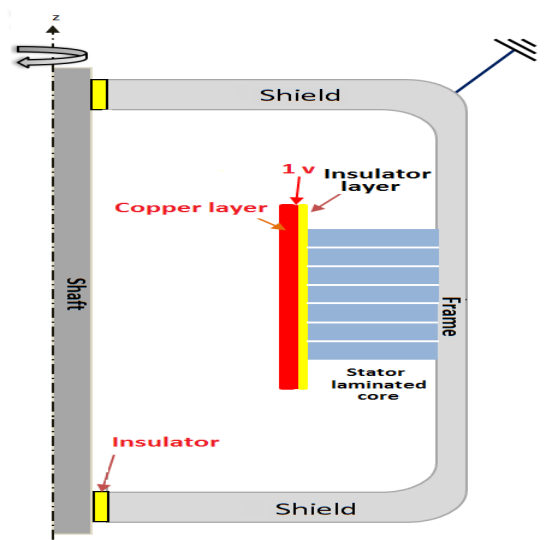

Fig.1: Outline of the test model 2D axial symmetry 
B. Finite element resolution with axial symmetry (2D):

Table I : Geometrical characteristics

\begin{tabular}{|l|c|}
\hline \multicolumn{1}{|c|}{ Description } & Value \\
\hline External radius of an iron sheet & $0.0875 \mathrm{~m}$ \\
\hline Inner radius of an iron sheet & $0.05 \mathrm{~m}$ \\
\hline Thickness of an iron sheet & $500 \mu \mathrm{m}$ \\
\hline $\begin{array}{l}\text { Thickness of insulator between the iron sheets and } \\
\text { the copper layer. }\end{array}$ & $200 \mu \mathrm{m}$ \\
\hline Thickness of the insulator between two iron sheets & $\mathbf{1 0 \mu \mathrm { m }}$ \\
\hline External radius of the frame & $0.0975 \mathrm{~m}$ \\
\hline Inner radius of the frame & $0.0875 \mathrm{~m}$ \\
\hline Length of external side of the frame & $0.04 \mathrm{~m}$ \\
\hline $\begin{array}{l}\text { Length of inner side of the frame (between stator } \\
\text { laminated part and the end shield) }\end{array}$ & $0.0097 \mathrm{~m}$ \\
\hline $\begin{array}{l}\text { Thickness of the insulator between the frame and } \\
\text { the copper layer. }\end{array}$ & $0.010 \mathrm{~m}$ \\
\hline External radius of the end shield & $0.0875 \mathrm{~m}$ \\
\hline Inner radius of the end shield & $0.035 \mathrm{~m}$ \\
\hline Shaft radius & $0.015 \mathrm{~m}$ \\
\hline Shaft length & $0.03 \mathrm{~m}$ \\
\hline
\end{tabular}

Table II; physic characteristics

\begin{tabular}{|c|c|}
\hline Model Components & Used materials \\
\hline Frame, shield shaft, Stator laminated core & Iron \\
\hline All insulators & Air \\
\hline
\end{tabular}

The above assumptions allow us to exploit the axial symmetry of the studied geometry. The COMSOL Multiphysics software has been used for FE modeling (Fig.2). The geometrical parameters and used materials in the developed model are reported in Table I and Table II.

As we can see in Table I, there is a great difference between the thickness of metallic sheet $(500 \mu \mathrm{m})$ and the insulation layers, between each two sheets $(10 \mu \mathrm{m})$. Under these conditions, the number of mesh elements increases greatly. Therefore, solving the problem is time consuming. Hence, in order to make possible the resolution of the model, only 7 iron sheets were modeled.

To take into account all electromagnetic phenomena, i.e. induced current, electric current and displacement current, we used AC/DC module, Quasi-Statics \& Electromagnetic formulations:

$$
\left\{\begin{array}{c}
-\nabla \cdot\left(\left(j \omega \sigma-\omega^{2} \varepsilon_{0} \varepsilon_{r}\right) A+\left(\sigma+j \omega \varepsilon_{0} \varepsilon_{r}\right) \nabla V-J^{e}\right)=0 \\
\left(j \omega \sigma-\omega^{2} \varepsilon_{0} \varepsilon_{r}\right) A+\nabla \times\left(\mu_{0}^{-1} \mu_{r}^{-1} \nabla \times A\right) \\
+\left(\sigma+j \omega \varepsilon_{0} \varepsilon_{r}\right) \nabla V=J^{e}
\end{array}\right.
$$

With: $A$ is the magnetic potential, and $V$ is the electric potential, $J^{e}$ the external current density (equal to zero in our case).

While the magnetic potential has radial and axial components (only $\mathrm{r}$ and $\mathrm{z}$ directions), the magnetic field has only an orthoradial component. The current density has only radial and axial components too.

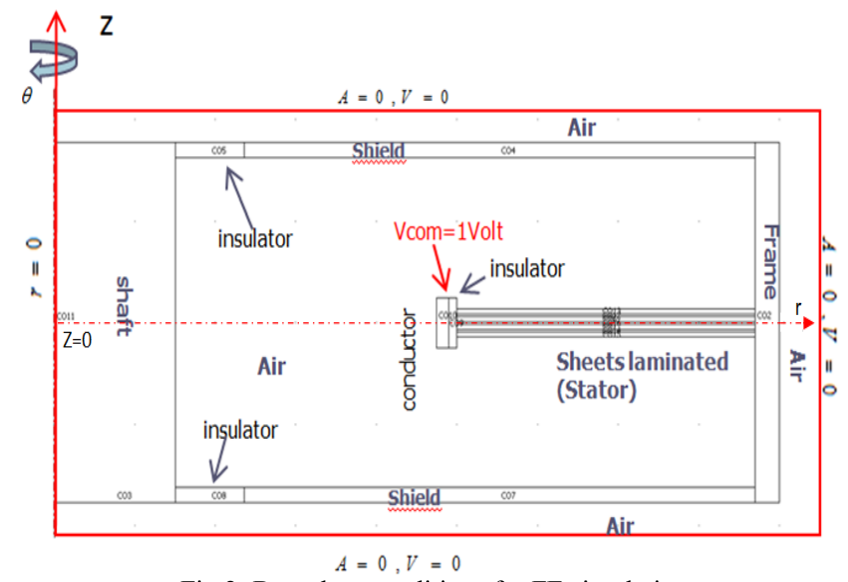

Fig 2: Boundary conditions for FE simulation

A common voltage is applied to all external sides of the copper layer to ensure equipotentiality and thus, excludes its impedance. The operating frequency is $10 \mathrm{kHz}$.

Homogeneous Dirichlet conditions $\mathrm{A}=0$ and $\mathrm{V}=0$ are imposed on the boundaries delimiting the domain of study. The axis of revolution is defined by $r=0$. The other boundaries are defined by the continuity conditions between interfaces (2-4).

$$
\overrightarrow{H_{t 1}}=\overrightarrow{H_{t 2}} \quad \text { (2), } \quad \overrightarrow{J_{n 1}}=\overrightarrow{J_{n 2}} \quad \text { (3), } \quad \overrightarrow{E_{t 1}}=\overrightarrow{E_{t 2}}
$$

Where $H$ is the magnetic field, $E$ is the electric field, $J$ is the current density.

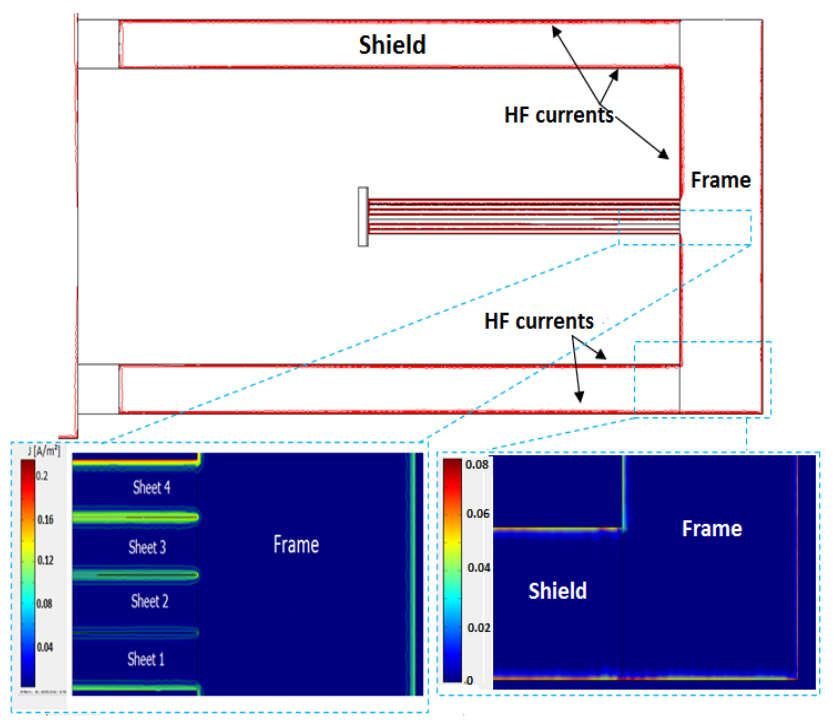

Fig.3: The normal current density distribution for a frequency $\mathrm{f}=10 \mathrm{kHz}$

\section{Post-processing:}

Fig. 3 shows the distribution of the current density obtained by finite elements analysis in a region situated between the frame and the lamination (light blue dotted line). We can notice that, due to skin effect, the HF currents are concentrated in the surface of each component of the structure (lamination sheets, frame...). In addition, these HF currents are divided 
into two parts; the first part flows through the inner radius of the frame, then inner face of the left end shield, and external face of the left end shield and reaches the ground connection (arrows in continuous red lines in Fig.4). The second part of the HF current flows through the inner radius of the frame, the inner face of the right end shield, the external face of the right end shield to reach the ground (arrows with dashed green lines in Fig.4). This current distribution is due to the competition between the impedances of the first and the second path.

The distribution of the current density presented in Fig.5 confirms that the HF currents are focused on the surface of the lamination sheets. We can also notice that the current density is increasing from one surface to the other in the same iron sheet. The increase of current density from one face to the other $\left(s h_{n}\right)$, for the same lamination sheet, is due to the summation of the current coming from neighbour sheet through the frame with the one coming through the stray capacitance between the winding and the laminated core.

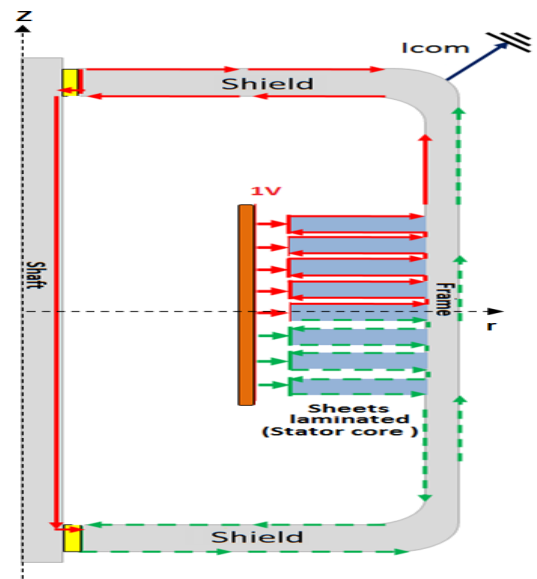

Fig.4: Paths of HF common mode currents in the motor

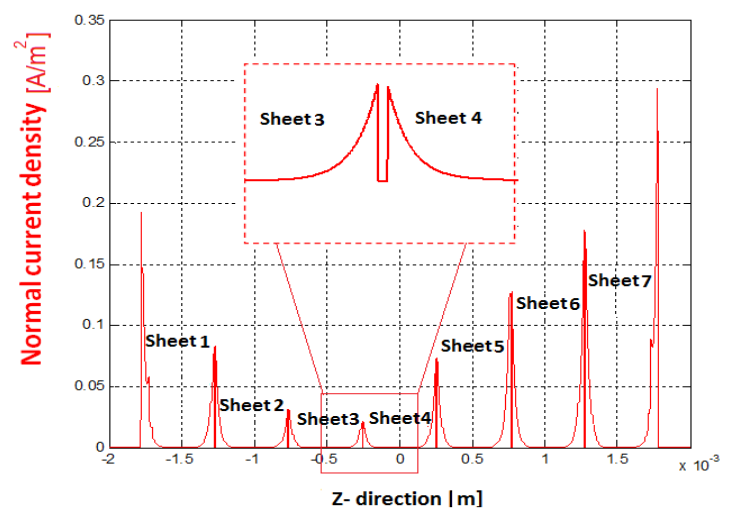

Fig.5: The normal current density distribution in stator sheets for $\mathrm{f}=10 \mathrm{kHz}$

These results also confirm that HF currents flow through iron sheets surfaces but not directly through the frame, as it was presented in [5]. This particular path, that could be called to be a "zigzag" way, depends on different parameters: the frequency of the windings voltage, the physical characteristics of the materials, the contact between the stator laminated parts and the frame. Indeed, at the passage interface $(\Omega)$ between frame part and one iron sheet part (Fig.6), the current density can be expressed as following:

Domain 1 (frame):

$$
\overrightarrow{J_{1}}=\overrightarrow{J_{r 1}}+\overrightarrow{J_{z 1}}=J_{r 1} \vec{n}+J_{z 1} \vec{t}
$$

Domain 2 (iron sheet):

$$
\overrightarrow{J_{2}}=\overrightarrow{J_{r 2}}+\overrightarrow{J_{z 2}}=J_{r 2} \vec{n}+J_{z 2} \vec{t}
$$

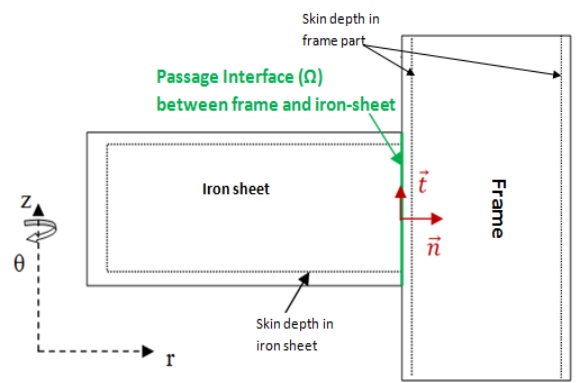

Figure.6: descriptive scheme of the passage interface between one iron sheet and a part of frame

From (3) and (4):

$$
\begin{aligned}
& J_{r 1}=J_{r 2} \quad(7), \quad J_{z 2}=\frac{\sigma_{2}}{\sigma_{1}} J_{z 1} \\
& \text { With: } J_{z 1}=\sigma_{1} E_{t 1} \text { and } J_{z 2}=\sigma_{2} E_{t 2}
\end{aligned}
$$

Expressions (7) and (8) allow finding a relation between the current densities in the two domains (frame, iron sheet) at an passage interface.

$$
=>\left\{\begin{array}{l}
\overrightarrow{J_{1}}=J_{r 2} \vec{n}+\frac{\sigma_{1}}{\sigma_{2}} J_{z 2} \vec{t} \\
\overrightarrow{J_{2}}=J_{r 2} \vec{n}+J_{z 2} \vec{t}
\end{array}\right.
$$

As mentioned above, the magnetic field has only the azimuthal component $H_{\theta}$. Then, using (2):

$$
\begin{gathered}
H_{t 1}=H_{t 2}=H_{\theta} \\
\text { So, } \quad\left\|\overrightarrow{\operatorname{rot}\left(H_{t 1}\right)}\right\|=\left\|\overrightarrow{\operatorname{rot}\left(H_{t 2}\right)}\right\|
\end{gathered}
$$

The current density in the iron sheet has only a component $J_{r}$ according to $\vec{r}$ axis, which is perpendicular to the interface surface:

$$
\left\|\overrightarrow{\operatorname{rot}\left(H_{t 2}\right)}\right\|=J_{r 2}
$$

Moreover, the current density in the frame has only a component $J_{z}$ according to $\vec{z}$ axis, which is tangential to the interface surface:

$$
\left\|\overrightarrow{\operatorname{rot}\left(H_{t 1}\right)}\right\|=J_{z 1}
$$

Using (9), (10) and (11):

$$
J_{z 1}=J_{r 2}
$$

Therefore, 


$$
\left\{\begin{array}{l}
\overrightarrow{J_{1}}=J_{z 1} \vec{n}+J_{z 1} \vec{t} \\
\overrightarrow{J_{2}}=J_{z 1} \vec{n}+\frac{\sigma_{2}}{\sigma_{1}} J_{z 1} \vec{t}
\end{array}\right.
$$

The magnetic field induced in the iron sheet, as well as in the frame, has a high frequency which will lead to a significant decrease of its magnitude beyond the skin depth $(\delta)$ indeed even a cancellation, along $\mathrm{z}$ axis in the iron sheet. Therefore, for $\mathrm{z}>\delta$ :

$$
\begin{gathered}
\mathrm{H}(\mathrm{z}>\delta)_{\mathrm{t} 2}=\mathrm{H}(\mathrm{z}>\delta)_{\mathrm{t} 1} \approx 0 \\
\left\|\overrightarrow{\operatorname{rot}\left(H(z>\delta)_{t 1}\right)}\right\|=\left\|\overrightarrow{\operatorname{rot}\left(H(z>\delta)_{t 2}\right)}\right\| \approx 0 \\
=>J_{z 1}=J_{r 2} \approx 0
\end{gathered}
$$

Then,

$$
\left\{\begin{array}{l}
\overrightarrow{J_{1}}=J_{r 2} \vec{n}+J_{z 1} \vec{t} \approx 0 \\
\overrightarrow{J_{2}}=J_{r 2} \vec{n}+\frac{\sigma_{2}}{\sigma_{1}} J_{z 1} \vec{t} \approx 0
\end{array}\right.
$$

These results explain why HF currents flowed through iron sheets surfaces and not directly through the frame according a "zig-zag" way. This phenomenon is governed by the boundary conditions, the physic parameters of domains $(\mu, \varepsilon$, and $\sigma)$ and frequency. For low frequencies $(\mathrm{f}<1 \mathrm{kHz})$, the skin depth in the iron sheet is approximately equal to the half of the depth of the sheet. Therefore, the continuity of current circulation is assured in the bottom of the frame in contact with the laminated stator core. Thus the "zigzag" effect is reduced in this case (Fig.7).

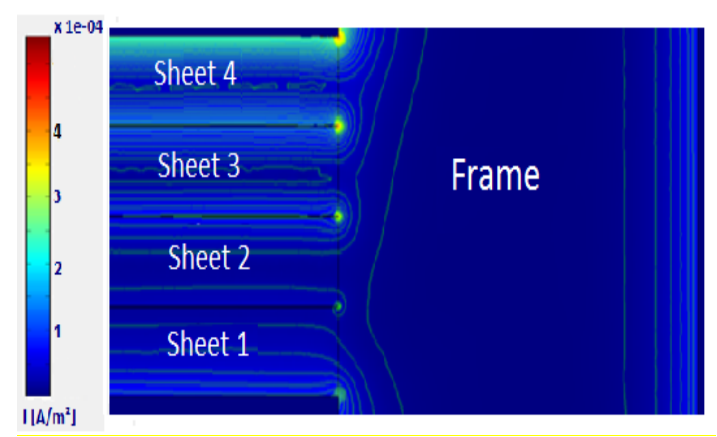

Fig.7: The normal current density distribution for a frequency $\mathrm{f}=100 \mathrm{~Hz}$

\section{IMPACT OF THE POSITION AND THE NUMBER OF GROUNDS}

In order to study the ground position influence on the propagation paths, we used the FE model developed previously. However, in contrast to previous simulations (Fig. 2), in Fig. 8 the ground point has been placed in the middle of external surface of the frame instead of the end of the frame. As we can see on Fig 8, regardless of the grounding position, the HF currents always flow along the surfaces of metallic parts to the grounding point. In addition, it should be noted that, the HF currents are divided into two equal parts. As pointed out previously, this observed distribution is only the result of competition between impedances. Thus, we deduce that the equivalents impedances of the two propagations paths are equal (in the x simulation case of Fig.8).

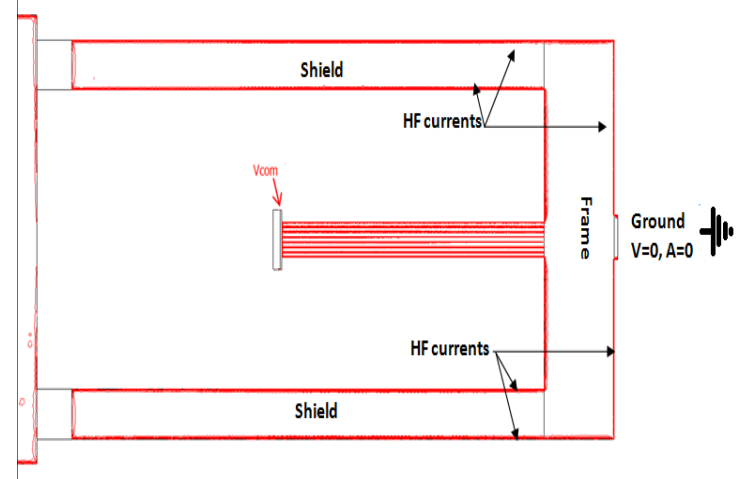

Fig.8: The normal current density distribution for ground point placed on external inner of the frame $(\mathrm{f}=10 \mathrm{kHz})$

The second issue addressed in this section is the number of grounding. In Fig. 10, the simulation model contains two grounding points placed at the ends of the frame. We can notice two propagation paths of HF currents but in this case (Fig. 10), there is no current on the external surface of the frame. So, the number of grounding points has also a significant influence on the propagation way of HF currents.

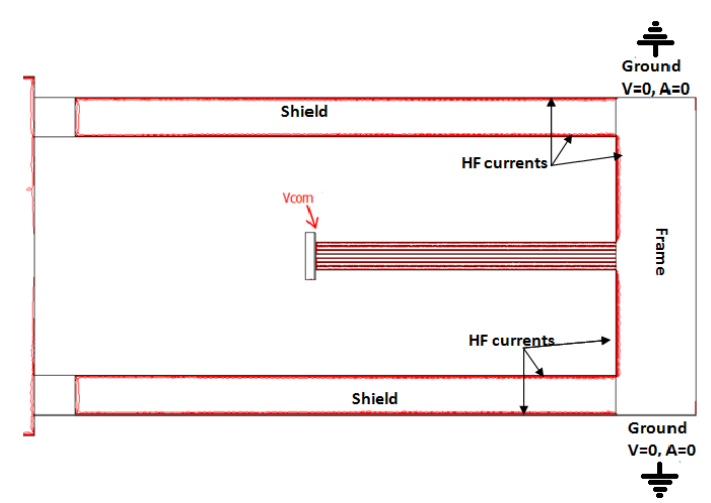

Fig.9: The normal current density distribution in presence of two grounds points for a frequency $\mathrm{f}=10 \mathrm{kHz}$.

Despite the simplification of the developed FE models are, obtained results allow understanding the phenomena of propagation of HF currents and their distribution in the metal parts. Indeed, it is clear that in the case of a real motor, the HF currents should not necessarily divide into two propagations paths (or equal paths), but it is certain that their distribution is governed by the competition between impedances equivalent to propagation paths, between injection (windings) and the grounding point. Therefore, these paths will be influenced by the position and the number of grounding points.

\section{EXTRACTION OF THE COUPLING BETWEEN IRON SHEETS FROM FEA:}

From the previous FEA, an equivalent circuit model of the propagations paths in metallic parts was developed [14]. This circuit model takes into account the physical characteristics, 
geometrical parameters, and the curve effect due to the cylindrical form of the studied topology on the one hand, and on the other hand, the flux leakage between two adjacent surfaces of lamination sheets, due to the magnetic field in the air-gap between iron sheets.

In this section, we describe the steps of identifying and extracting the mutual inductance $(\mathrm{Zm})$, which represents the leakage between adjacent iron sheets, from FE modeling.

\section{A. Modeling of iron sheet impedance}

Using again the assumption proposed in [7], geometrical and physical characteristic (table I, II), a model of one iron sheet by FE method was realized (Fig.10), wherein all electromagnetic phenomena were considered. As we can see in Fig.10, a voltage is imposed between the two sides of the iron sheet. The operating frequency is $10 \mathrm{kHz}$.

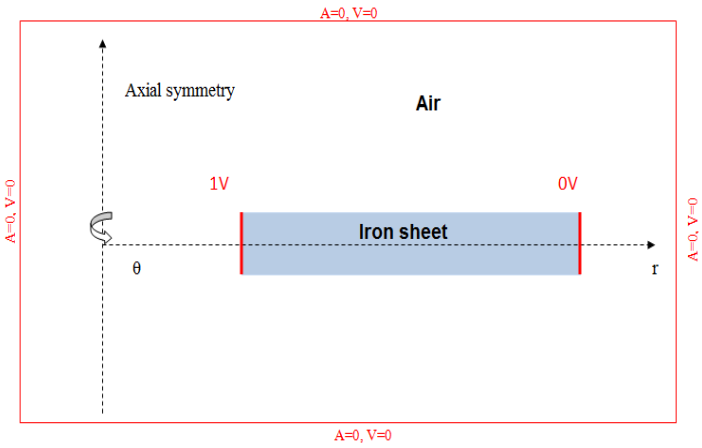

Fig.10 : Descriptive figure of FEA of one iron sheet

As we can see in figure 11 , the normal density current is divided into two equal parts and also focused in the surfaces of the iron sheet. Therefore, we can assign an RL circuit (impedance $Z_{\text {surface }}$ ) to each surface limited by the skin depth $[6,8]$. The electrical model of the iron sheet is presented in Fig12. In this paper, $Z_{\text {surface }}$ was extracted from FE simulation.

$$
Z_{\text {surface }}=2 Z_{\text {sheet }}
$$

Where, $Z_{\text {sheet }}$ is the equivalent impedance of the whole iron sheet. $Z_{\text {surface }}$ is the equivalent impedance of one surface of the iron sheet.

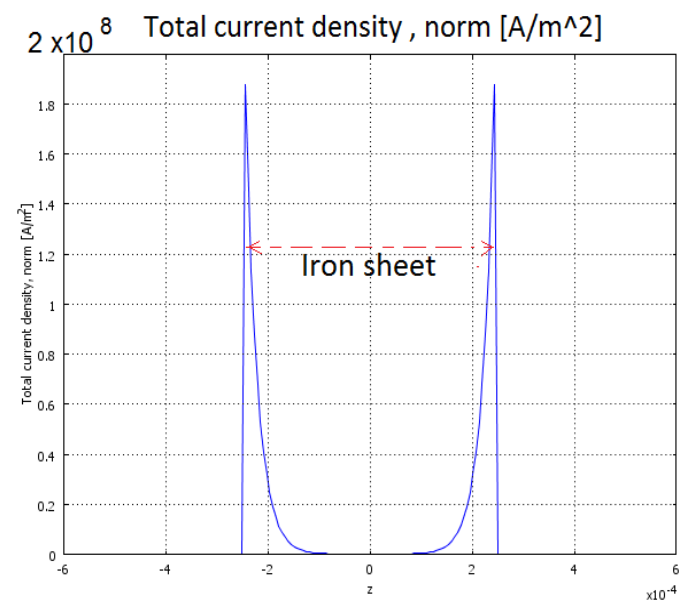

Fig.11: The normal current density distribution on the iron sheet according to axis $\mathrm{z}$ and for distance $\mathrm{r}=0.0715 \mathrm{~m}$

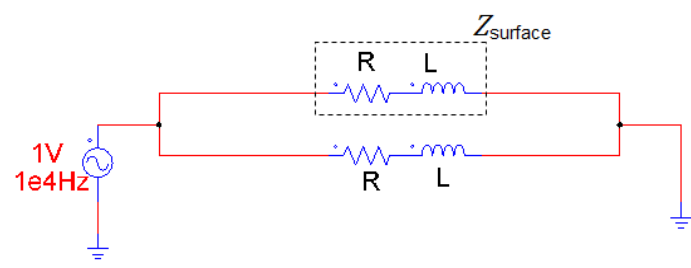

Fig. 12 : Equivalent electric figure of FEA of one iron sheet

\section{B. Extracting of mutuelle impedance:}

In this part, two iron sheets are modeled. The air-gap between the two iron sheets is $10 \mu \mathrm{m}$. A voltage is imposed between both sides of the two iron sheets (Fig.13); using the same voltage port. The operating frequency is $10 \mathrm{kHz}$.

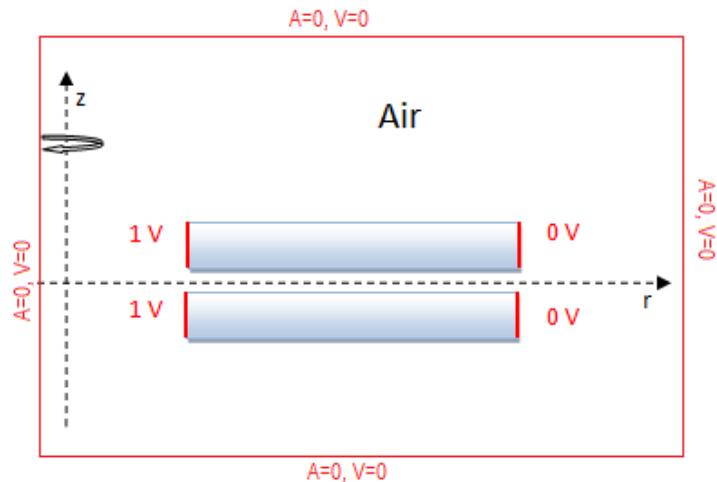

Fig. 13 : Descriptive figure of FEA of two adjacent iron sheets

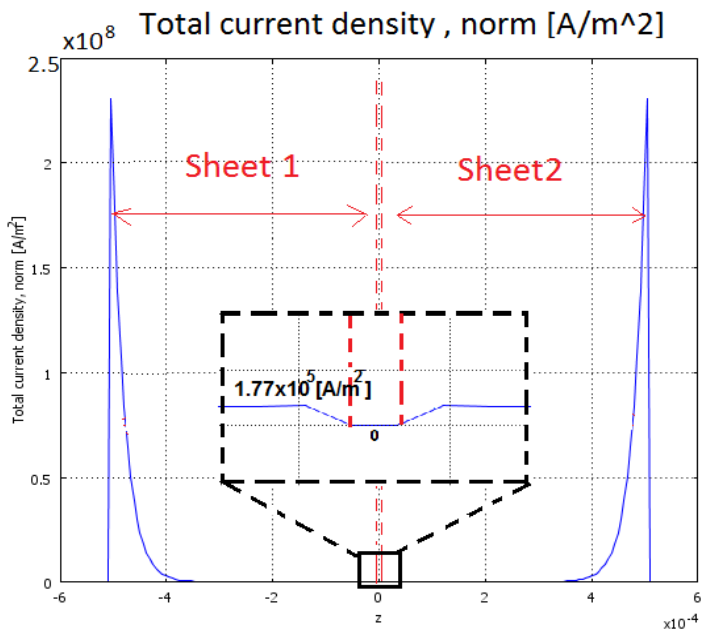

Fig.14 : The normal current density distribution on the two iron sheets according to axis $\mathrm{z}$ and for distance $\mathrm{r}=0.0715 \mathrm{~m}$

The simulation results, Fig.14, show that the current is mainly flowed through the nonadjacent surfaces of the iron sheets. As in the first steps, we assign an impedance $Z_{\text {surface }}\left(Z_{1: 4}\right)$ to each surface limited by the skin depth. Then, the leakage between adjacent surfaces of the iron sheets; which is due to magnetic and electric field in the air gap, is represented by the mutual impedance $Z_{\mathrm{M}}$. The electrical model of the two iron sheet is represented in Fig. 17.

From this model and by applying the Kirchhoff's law, we have: 


$$
\left\{\begin{array}{c}
U=Z_{1} I_{1} \\
U=Z_{2} I_{2}+Z_{M} I_{3} \\
U=Z_{3} I_{3}+Z_{M} I_{2} \\
U=Z_{4} I_{4}
\end{array}\right.
$$

As the two sheets are the same:

$$
Z_{1}=Z_{2}=Z_{3}=Z_{4}=Z_{\text {surface }}
$$

And then, $\quad I_{1}=I_{4}, \quad I_{2}=I_{3}$

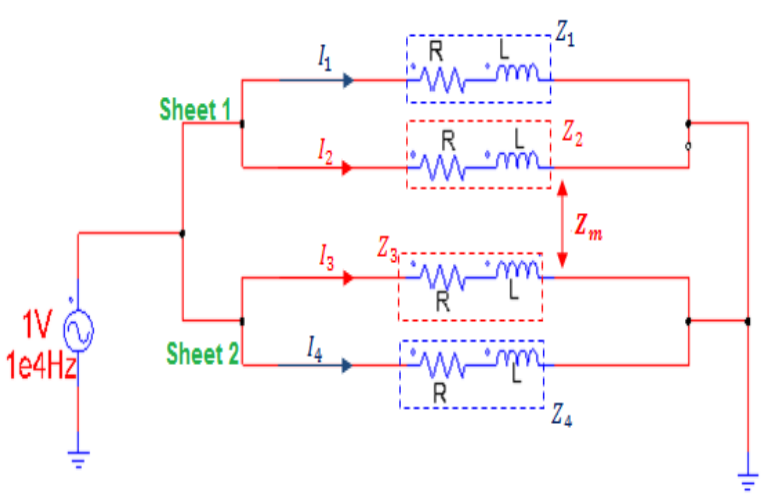

Fig.15 : Equivalent electric figure of FEA of two adjacent iron sheets

Using theses equations (17-19) and the value of $Z_{\text {surface }}$ (extracted from the first step), the mutual impedance $Z_{M}$ was calculated. The impact of this parameter is summarized in table III. Indeed, table III contains the results of calculating equivalent impedances of the whole of 3, 5 and 7 iron sheets electrically connected in parallel. As we can see, the neglecting of $\mathrm{Z}_{\mathrm{M}}$ will introduce about $64 \%$ of error versus finite $\mathrm{FE}$ simulation on the estimation of equivalent impedances of 3 iron sheets and about $82 \%$ for 7 iron sheets. Although that $Z_{M}$ has a trivial impact on the estimation of $I_{\text {com }}$ for frequencies lower than $1 \mathrm{MHz}$ as pointed out in [14], it has a significant influence on the calculation of common-mode flux.

\begin{tabular}{|c|c|c|c|}
\hline \multirow{2}{*}{$\begin{array}{l}\text { Calculating } \\
\text { methods }\end{array}$} & \multicolumn{3}{|c|}{ Equivalent impedance $(\Omega)$} \\
\hline & 3 sheets & 5 sheets & 7 sheets \\
\hline $\begin{array}{l}\text { Finite elements } \\
\text { (FE) }\end{array}$ & $\begin{array}{l}(1.67+1.83 \text { i) } \\
10-4\end{array}$ & $\begin{array}{l}(1.56+1.75 \text { i) } \\
10-4\end{array}$ & $\begin{array}{l}(1.32+1.90 \mathrm{i}) \\
10-4\end{array}$ \\
\hline $\begin{array}{l}\text { Analytical with } \\
Z_{m}\end{array}$ & $\begin{array}{l}(1.67+1.82 \text { i) } \\
10-4\end{array}$ & $\begin{array}{l}(1.57+1.71 \mathrm{i}) \\
10-4\end{array}$ & $\begin{array}{l}(1.33+1.85 \text { i) } \\
10-4\end{array}$ \\
\hline $\begin{array}{l}\text { Analytical } \\
\text { neglecting } Z_{\mathrm{m}}\end{array}$ & $\begin{array}{l}(5.97+6.52 \text { i) } \\
10-5\end{array}$ & $\begin{array}{l}(3.58+3.91 \text { i) } \\
10-5\end{array}$ & $\begin{array}{l}(2.35+3.19 \mathrm{i}) \\
10-5\end{array}$ \\
\hline
\end{tabular}

Table III

\section{CONCLUSION:}

A detailed finite elements model was developed to identify the different parameters which rule the propagation of $\mathrm{HF}$ currents in metallic parts of an AC induction machine. This FEA allowed analyzing the different paths followed by HF current, including its "zigzag" flowing in the lamination and in the other parts of the machine. The "zigzag" path is governed by the frequency, the properties of materials and geometry. Also, mutual impedance was identified between two adjacent iron sheets. In addition, the position and number of grounding points obviously contribute significantly to the path of these HF currents. The results of the analysis have been used to establish a circuit model of propagation path of HF current in metallic parts [14].

\section{REFERENCES}

[1] S. Chen, «Generation and suppression of conducted EMI from inverterfed motor drives», Conference Record of the 1999 IEEE Industry Applications Conference. Thirty-Forth IAS Annual Meeting (Cat. No.99CH36370).

[2] S. Chen, T.A. Lipo and D.Fitzgerald, « Measurement and Analysis of Induction Motor Bearing Currents PWM Inverter Driver», in Proceedings of the International Aegean Conference on Electrical Machines and Power Electronics, Kusadasi, Turkey, pp.289-296.

[3] S. Chen, Lipo, T. A. and Novotny, D. W. (1996c), in Conference Record of the 31st IEEE-IAS Annual Meeting, IAS'96, San Diego, CA, vol. 1, pp. 162-167 « Circulating type motor bearing current in inverter drives »,

[4] D. Busse. and Erdman, J. and Kerkman, R.J. and Schlegel, D. and Skibinski, G « The effects of PWM voltage source inverters on the mechanical performance of rolling bearings $\gg$. Industry Applications, IEEE Transactions on MARCH/APRIL 1997, Vol 33, pages 567—576.

[5] A. Muetze, A. Binder and H, Vogel, « Experimental Evaluation of the Endangerment of Ball Bearings due to Inverter-Induced Bearing Currents»,Industry Applications Conference, 2004. 39th IAS Annual Meeting. Conference Record of the 2004 IEEE.

[6] P. Mäki-Ontto and J. Luomi, « Common-mode flux calculation of ac machines », in Proceedings of the International Conference on Electrical Machines, ICEM 2002, Bruges, Belgium, 2002.

[7] P. Mäki-Ontto and J. Luomi, « Induction motor model for the analysis of capacitive and induced shaft voltages », in Conference Record of the International Electric Machines and Drives Conference, IEMDC 2005, San Antonio, TX, 2005.

[8] A. Muetze and A. Binder, «Calculation of Circulating Bearing Currents in Machines of Inverter-Based Drive Systems», IEEE Transactions On Industrial Electronics, vol. 54, No. 2, April 2007.

[9] A. Muetze, De Gersem, H. and Weiland, « Influence of teeth and cooling ducts on the high-frequency common mode flux of inverter-fed AC machines ", T. Industry Applications Conference, 2005. Fourtieth IAS Annual Meeting. Conference Record of the 2005

[10] B. Mirafzal. and Skibinski, G. and Tallam, R. and Schlegel, D. and Lukaszewki, "Universal induction motor model with low-to-high frequency response characteristics ", Industry Applications Conference, 2006. 41 st IAS Annual Meeting. Conference Record of the 2006 IEEE. Pages 423-433.

[11] U.T, Shami, and Akagi, $\mathrm{H}$ « Identification and discussion of the origin of a shaft end-to-end voltage in an inverter-driven motor», Power Electronics, IEEE Transactions on 2010, volume 25, pages 1615-1625.

[12] Kohji Maki, Hiro Funato and Liang Shao, « Motor Modeling for EMC simulation by 3-D Electromagnetic Field Analysis», Electric Machines and Drives Conference, IEMDC'09.IEEE international 2009.pages 103108.

[13] O. Magdun and A.Binder " An iron core Impedance Model for calculating High Frequency Common Mode Currents and Shaft Voltages in Inverter-fed AC machines " International Symposium on Power Electronics, Electrical Drives, Automation and motion.

[14] N. Boucenna, S. Hlioui, B. Revol and F. Costa " Modeling of the propagation of high-frequency currents in AC motors ", international symposium on electromagnetic compatibility, EMC Europe ROMA, Italy, 2012. 